\title{
INCIDENCE, TRENDS AND RISK FACTORS FOR ECTOPIC PREGNANCY IN CASES REFERRED TO NALANDA MEDICAL COLLEGE AND HOSPITAL PATNA
}

\author{
Dr. Kalpana \\ Prasad*
}

\section{Dr. Mamta Singh} Dr. Richa Kumari
Post Graduate Student, Dept. Of Obs \& Gynae, N.M.C.H, Patna (Bihar). ${ }^{*}$ Corresponding Author

ABSTRACT INTRODUCTION: Ectopic pregnancy occurs at a rate of about 1-2\% of pregnancies and can occur in any sexually active woman of reproductive age. The incidence has been increasing for years and currently it is two to three times higher than it was 20 or 25 years ago. OBJECTIVE: To assess the incidence and trends of ectopic pregnancy in a tertiary care hospital of Bihar and to evaluate the relevance of the risk factors associated with it. METHODS: A retrospective study was designed to assess frequency of ectopic pregnancy and to evaluate the relevance of the known risk factors during 2018 -2019 in Nalanda Medical College and Hospital. All the data were collected from the case record of patients and charted in an excel sheet. Simple frequencies and percentages were obtained for various variables. RESULT: The incidence of ectopic pregnancy was 12.5 per thousand of deliveries. Maximum (72.5\%) cases were in the age group of 21 to 30 years and most of cases (40\%) were nulliparous. About half (47.5\%) of cases were suffering from pelvic inflammatory disease. The commonest site of ectopic pregnancy was in the ampullo-isthmic region (82.5\%). All patients underwent exploratory laparotomy. Majority $(45 \%)$ underwent total salpingectomy while fallopian tubes were conserved in a few $(7.5 \%)$ of cases. No mortality was encountered in this series. CONCLUSION: By identifying the risk factors and diagnosing the patient by ultrasonographic examination at the earliest at 6 weeks, it is possible to improve the prognosis to reduce the morbidity and mortality associated with ectopic pregnancy.

KEYWORDS : Ectopic Pregnancy, Exploratory Laparotomy, Primigravida, Fallopian Tubes, Ultrasonography, Pelvic Inflammatory Disease.

\section{INTRODUCTION}

Ectopic pregnancy is the most life-threatening emergency in early pregnancy leading to maternal death[1]. Several risk factors for ectopic pregnancy have been identified including a history of pelvic inflammatory disease (PID), smoking at the time of conception, previous ectopic pregnancy, previous pelvic surgery, induction of ovulation and intrauterine device usage[2]. Such abnormalities of the tubes prevent normal transport of the fertilized egg to the uterus. The most common site of ectopic implantation is the fallopian tube. Other sites such as the abdomen, ovary, or cervix are far less common but are associated with higher mortality. This higher mortality is due to delayed detection at these sites resulting in massive bleeding that can result if rupture occurs at these sites. Ectopic pregnancy occurs at a rate of about $1-2 \%$ of pregnancies and can occur in any sexually active woman of reproductive age. The incidence has been increasing for years and currently two to three times higher than it was 20 or 25 years ago. The increase in incidence in the past few decades is thought to be due to two factors:-

1. Increased incidence of salpingitis (infection of the fallopian tube, usually due to a sexually transmitted disease (STD), such as cl hlamydia or gonorrhea), and

2. improved ability to detect ectopic pregnancies.

Blood loss is the major cause (about $85 \%$ ) of death in ectopic pregnancies. Misdiagnosis leading to delayed treatment contributed to about half of deaths. An ectopic pregnancy is a pregnancy that implants and develops outside the endometrial lining of the uterus. $97 \%$ of ectopic pregnancies occur in the fallopian tube. $80 \%$ of these occur in the ampulla region of the tube. About $10 \%$ occur in the isthmus region and about $5 \%$ in the infundibulum region. Only about $3 \%$ occur in the interstitial portion of the fallopian tube. Rarely do ectopic pregnancies occur in the ovary, in the cervix, in caesarean scar or in the abdomen. Although these non-tubal and interstitial ectopic pregnancies are rare, they represent nearly $20 \%$ of deaths due to ectopic pregnancies. This high danger to life at these locations results from massive bleeding when these pregnancies rupture (These abnormal pregnancy locations, unlike the uterus, cannot expand enough to fit the growing embryo; thus these structures can eventually rupture, causing profuse bleeding. Most abdominal pregnancies occur after the embryo first implants in the fallopian tube, after which it is expelled from the fimbrial opening of the tube and then implants in the abdomen. An unusual type of abdominal pregnancy may implant in the spleen or liver, which causes massive lethal bleeding in the abdomen.

The most common symptoms that a woman presents to a doctor are abdominal pain (90-100\% of women), absence of menses ("not getting your period") (75-90\%) and unexpected bleeding through the vagina (50-80\%) Before rupture occurs, there might be just a vague soreness or spastic (colic) pain in the abdomen. Most common sign is abdominal and pelvic pain. Adnexal mass (50\%), smaller enlargement of uterus than would be expected in a normal pregnancy (33\%)., tachycardia and hypotension can be found with profuse blood loss. However, in most early ectopic pregnancies, no abnormal findings can be found. Surgery is done only if transvaginal ultrasonography shows an ectopic pregnancy in the fallopian tube or a mass around the ovary suggestive of an ectopic pregnancy. If nothing is seen on ultrasonography, it is not likely to be seen at surgery either, so continuous close follow-up or medical treatment can be done. Persistent ectopic pregnancy is seen in $8.3 \%$ of women treated by laparoscopic salpingostomy and in $3.9 \%$ of these treated by laparotomy. However, this also depends on the expertise of the laparoscopic surgeon. (Although in our Institute laparoscope is not available )

\section{MATERIAL AND METHOD}

This hospital based retrospective study was conducted at Nalanda Medical College and Hospital on 180 cases operated in obstetrics and gynaecology department during January 2018 to December 2019. Data was analysed 
retrospectively using the case-sheets and operative notes. This hospital caters mainly the urban population nearby. The detailed history (Age, obstetric history, amenorrhea, pain abdomen, bleeding per vaginum, predisposing factors), Investigation (urine for pregnancy test, Ultrasound) and treatment modalities recorded. All patients underwent Exploratory Laparotomy. Number of blood transfusions (in units) were noted.

\section{RESULT}

We conducted the study over a period of 2 years. The total numbers of deliveries were 14400 . The total number of ectopic pregnancies turned out to be 180. It gave an incidence of 1.25 $\%$ or 12.5 per 1000 deliveries. The highest numbers of patients, $72.5 \%$ were in the age group of 21 to 30 years (Table 1 ). Though we encountered $5 \%$ of teenagers ( 9 cases).We encountered maximum cases nulliparous $40 \%$ ( 72 cases), having one issue and two issues to be $20 \%$ and $32.5 \%$ respectively (Table 2 ). A few $(7.5 \%)$ had three or more issues. Maximum (87.5\%) reported with pain abdomen. Bleeding per vagina encountered in $67.5 \%$ for variable period. $90 \%$ of cases had history of amenorrhea ranging from 6 weeks to 18 weeks and rest of $10 \%$ of cases had no history of amenorrhea. About half of the cases $(47.5 \%)$ had pelvic inflammatory disease (Table 3). About a quarter of cases (22.5\%) were treated for infertility. One tenth of cases undergone some tubal surgeries. Five percent of patients had previous ectopic pregnancies. 4 cases underwent IUCD insertion and 4 cases had caesarean section. The most important and most basic feature, can be done bed side, pulse examination revealed all had a tachycardia ( $95 \%$ of cases) and $5 \%$ of cases were in shock.

Almost all patient $97.5 \%$ were anaemic. Half of the cases (50\%), had $\mathrm{Hb}$ in range of $4-7 \mathrm{gm} \%$ and $47.5 \% \mathrm{Hb}$ in range of 8 $10 \mathrm{gm} \%$. Only a single case had $\mathrm{Hb}$ more than $10 \mathrm{gm} \%$.

The urine for pregnancy test was found to be reactive in all of cases. We used ultrasound as a routine in evaluation of ectopic pregnancy. It was conclusive in this study to show the site of pregnancy. All patients underwent exploratory laparotomy because of non-availability of laparoscopy in our institute. We encountered majority of ectopic pregnancies in ampullary and isthmic $(40 \%, 32.5 \%)$ region respectively (Table 4).

The majority of cases underwent unilateral salpingectomy (45\%) followed by salpingoophorectomy and Bilateral salpingectomy (32.5\% and $12.5 \%$ resp.). A few cases treated by partial salpingectomy and milking ( $2.5 \%$ and $7.5 \%$ each). All patients were given blood transfusions. Bilateral salpingectomy was done for family planning purpose in multiparous patients wishing for that.

About one third patients received a single unit of blood and majority two third, received more than two units of blood. In this series we did not encounter a single mortality.

Table 1: Age wise distribution of ectopic pregnancy cases in present study

\begin{tabular}{|l|c|}
\hline Age group & Number of cases $\mathbf{n}=\mathbf{1 8 0}(\%)$ \\
\hline$<20$ & $9(5)$ \\
\hline $20-25$ & $85(47.5)$ \\
\hline $26-30$ & $45(25)$ \\
\hline $31-35$ & $36(20)$ \\
\hline $36-40$ & $5(2.5)$ \\
\hline
\end{tabular}

Table 2: Parity in present study

\begin{tabular}{|l|c|}
\hline Parity & Number of cases $\mathbf{n}=180(\%)$ \\
\hline Nulliparous & $72(40)$ \\
\hline One issue & $36(20)$ \\
\hline Two issues & $58(32.5)$ \\
\hline Three or more & $14(7.5)$ \\
\hline
\end{tabular}

Table 3: Risk factors for ectopic pregnancy in present study

\begin{tabular}{|l|c|}
\hline Risk factors & $\begin{array}{c}\text { Number of patients } \\
\mathbf{n}=180(\%)\end{array}$ \\
\hline H/O PID & $85(47.5)$ \\
\hline H/O tubal surgery & $18(10)$ \\
\hline H/O previous caesarean section & $4(2.5)$ \\
\hline H/O previous ectopic & $9(5)$ \\
\hline H/O infertility treatment & $40(22.5)$ \\
\hline H/O IUCD insertion & $4(2.5)$ \\
\hline
\end{tabular}

PID: Pelvic inflammatory disease

Table 4: Site of ectopic pregnancy

\begin{tabular}{|l|c|}
\hline Site & Number of cases $\mathbf{n = 1 8 0}(\%)$ \\
\hline Ampullary & $72(40)$ \\
\hline Isthmic & $59(32.5)$ \\
\hline Fimbrial & $4(2.5)$ \\
\hline Isthmico-ampullary & $18(10)$ \\
\hline Interstitial & $23(12.5)$ \\
\hline Infundibular & $4(2.5)$ \\
\hline
\end{tabular}

Table 5: Modalities of management in present Study

\begin{tabular}{|l|c|}
\hline Management & $\begin{array}{c}\text { Number of patients } \\
\mathbf{n}=180(\%)\end{array}$ \\
\hline Milking & $14(7.5)$ \\
\hline Partial salpingectomy & $4(2.5)$ \\
\hline Total Unilateral salpingectomy & $80(45)$ \\
\hline Salpingo-oophorectomy & $58(32.5)$ \\
\hline Bilateral salpingectomy & $23(12.5)$ \\
\hline
\end{tabular}

Table 6: Symptomatology in present study

\begin{tabular}{|l|c|}
\hline Clinical features & $\begin{array}{c}\text { Number of cases } \\
\mathbf{n}=180(\%)\end{array}$ \\
\hline Lower abdominal pain & $168(93.54)$ \\
\hline Amenorrhea & $142(79.03)$ \\
\hline Cervical motion tenderness & $136(75.80)$ \\
\hline Adnexal mass or fullness & $113(62.90)$ \\
\hline Abnormal uterine bleeding & $130(72.58)$ \\
\hline Abdominal guarding and rigidity & $116(64.51)$ \\
\hline Syncope & $29(16.12)$ \\
\hline
\end{tabular}

\section{DISCUSSION}

Ectopic pregnancy is a common obstetrical disorder in early pregnancy all over the world that remains an important cause of maternal mortality and morbidity. In UK (CMSO 1990) ectopic pregnancies occurs aslin 300 intrauterine pregnancies, 12.5 per 1000 deliveries and constitute $11.5 \%$ of the maternal mortality. In India the incidence of ectopic pregnancy reported by the Indian Porwal Sanjay et al. / JPBMS, 2012, 163 Journal of Pharmaceutical and Biomedical Sciences (JPBMS), Vol. 16, Issue 16 council of medical research (ICMR 19990) task force in their multicentric case control study was 3.12 per 1000 pregnancies or 3.86 per 1000 live births in the hospital reported pregnancies.In our study group the incidence of ectopic pregnancies was 12.5 per 1000 deliveries [4,5]. A study conducted at BPKIHS, Nepal in which they found incidence was $2.92 \%$ of total gynecological admissions. In US based studies the incidence turned to be $1.9 \%$ of reported pregnancies.In our study $72.5 \%$ patients belonged to age group of 21 to 30 years. Same age group seems to be affected in a Mumbai based study.We found $40 \%$ of sufferers to be primigravida. A Kolkata based study too revealed the primigravida to be most of the cases.All patients brought to us had tachycardia while two were in a condition of shock. Majority had anemia and all received blood transfusion.The $85 \%$ of cases had 6 tol0 weeks amenorrhea and only $15 \%$ presented with amenorrhea more than 10 weeks. The same pattern seen in a Kathmandu based study[6].We found ampullary portion of tubes (40\%) and isthmus(32.5\%) to be most common sites.Priti S Vyas et al al also found $42.5 \%$ ectopic pregnancies in ampullary portion 
and $22.4 \%$ in isthmic portion of the tubes. Both right and left side of tubes involved with equal frequency.Poonam et al also not found any significant difference between two sides. The vaginal bleeding of variable period was found in $67.5 \%$ of cases almost same as in a Kolkata study [6] .The classic triad of bleeding per vaginum, amenorrhea and pain abdomen found in $45 \%$ cases only. It gives an importance of early diagnosis of ectopic pregnancies. The commonest predisposing factors PID (47.5\%), Infertility (22.5\%), Tubal surgeries (10\%), Previous ectopic pregnancies (5\%). In $7.5 \%$ of cases tubes were conserved which coincides with the study from Pakistan $[8,9]$. The most frequent procedure in cases is total salpingectomy (45\%), salpingoophorectomy in $32.5 \%$ of cases, the same finding described by Chinurgia in current trends[10].Currently ultrasound and serum biomarkers are used by clinicians for early diagnosis .To conclude patients having clinical features of ectopic pregnancy on ultrasound scan as positive adnexal mass with or without gestational sac, with or without fetal heart, or presence of adnexal mass along with hemoperitoneum, along with positive pregnancy test, assures diagnosis of ectopic pregnancy.

So, by reducing and identifying the risk factors and diagnosing the patients by ultrasonographic examination at the earliest at 6 weeks, it is possible to improve the prognosis so far as the morbidity and mortality and fertility are concern .

\section{REFERENCES}

1. Patel UM, Gandhi MR, Jani PS, Kakani CR, Thakor N Clinical profile and management of ectopic pregnancy in patients with ectopic pregnancy at GMERS medical college and hospital Dharpur-Patan, North Gujarat region, India. Int J Res Med Sci 2015; 3:841-5.

2. Vyas PS, Vaidya P. Epidemiology, diagnosis and management of ectopic pregnancy - An analysis of 196 cases. BHJ Orig Res Artic. Available from: html: file://e: lepidemiology, diagnosis and management of ectopic pregnancy. [Last accessed on 2015 Aug 22].

3. Lewis G. The Confidential Enquiry into maternal and child health (CEMACH), Saving Mothers live: reviewing maternal deaths to make mother hood safer 2003-2005. The Seventh Report of Confidential Enquiry into Maternal Deaths in United Kingdom, London (CEMACH). Edi (Dec) 2007; pp 93-4.

4. Anorlu RI, Oluwole A, Abudu OO, Adebajo S. Risk factors for ectopic pregnancy in Lagos, Nigeria. Acta Obstet Gynecol Scand 2005; 84: 184-8.

5. Shirish N Daftary,Shyam V Desai. Current concepts in management of ectopic pregnancies. Page no.92-93.

6. Poonam Uprety D Baneriee B. Ectopic Pregnancy-two years review from PKIHS, Nepal. Kathmandu University Med J(KUMJ).2005, Oct-Dec,3(4):365-9.

7. Priti S Vyas, Pratibha Vaidya. Epidemiology, Diagnosis and management of ectopic pregnancy-an analysis of 196 cases. http://www.bhj.org/journal/ 20004203 jul00/original 458.htm.

8. Majhi AK, Roy N,Karmakar KS,Banerjee PK .Department of obstet. And gynecol.NRS Medical college,Kolkata. Passim Ectopic pregnancy - an analysis of 180 cases. J Indian Med Assoc.20076 June; 105(6);308,310.312,

9. Segal S,Mercado R,Rivnay B. Minerva Ectopic pregnancy early diagnostic markers.Gynecol $2010 \mathrm{Feb} ; 62(1) ; 49-62$

10. Lozeau AM Potter B Department of Family Medicine, University of Wisconsin Medical School-Madison, USA. Diagnosis and management of ectopic pregnancy. Am Fam Physician. 2005 Nov 1;72(9):1707-14. 